\title{
LUZ, CÂMERA, (DESUMANIZ)AÇÃO: ENTRE O PEDAGÓGICO E A MANUTENÇÃO DA VIDA, O QUE É SER PROFESSOR/A EM TEMPOS DE PANDEMIA?
}

\author{
Erica Pereira dos Santos Nascimento ${ }^{\mathrm{i}}$ \\ Rita de Cassia de Oliveira e Silva ${ }^{\text {ii }}$
}

\begin{abstract}
Resumo: Uma crise sanitária global tem colapsado sistemas de saúde, perspectivas econômicas, políticas e educacionais. Dentre as tramas deste cenário, o objetivo deste artigo é discutir os sentidos da docência em tempos de pandemia e para isso buscamos visibilizar narrativas em experiências de relações, territórios e desafios de ser professor/a no contexto da docência em atividades remotas. Através de chamadas telefônicas, captamos os relatos de sete professores/as em experiências de lecionar atividades remotas emergenciais. Após a análise destes concluímos que as ações pedagógicas realizadas neste contexto indicam que a intensificação do trabalho docente também pode se dar por fatores subjetivos despertados pelas condições objetivas de mudanças no ambiente escolar e no seu entorno.
\end{abstract}

Palavras-chave: Pandemia; Educação básica; Professores; Crise sanitária.

\section{LUZ, CÁMARA, ACCIÓN (DESHUMANIZANTE): ENTRE LO PEDAGÓGICO Y EL MANTENIMIENTO DE LA VIDA ¿QUÉ SIGNIFICA SER MAESTRO EN TIEMPOS DE PANDEMIA?}

Resumen: Una crisis de salud global ha colapsado los sistemas de salud, las perspectivas económicas, políticas y educativas. Entre las tramas de este escenario, el objetivo de este artículo es discutir los significados de la enseñanza en actividades remotas. A través de llamadas telefónicas, capturamos los informes de siete maestros en experiencias de enseñanza en actividades remotas de emergencia. Después de analizar esto, concluimos que las acciones pedagógicas llevadas a cabo en este contexto indican la que intensificación del trabajo docente también puede ocurrir debido a factores subjetivos que se despiertan por las condiciones objetivas de los cambios en el entorno escolar y sus alrededores.

Palabras-clave: Pandemia; Educación primária; Maestros; Crisis de salud.

\section{Introdução: vivendo na incerteza, agindo na urgência}

Há quem diga que vivemos em guerra contra a Covid-19. Por essa analogia não podemos perder de vista que nas guerras quem não mata, tem grandes chances de morrer. No cenário da necropolítica (MBEMBE, 2018) alguns/algumas precisam morrer para que outros/as vivam. Nosso contraponto é que ninguém tem que morrer. Ninguém tem que matar. Nossa opção é a preservação da vida e dignidade humana. Dessa forma escolhemos pensar que o que vivemos é uma crise. Uma crise sanitária global anunciada como pandemia no dia 
11 de março de 2020 pela Organização Mundial de Saúde (OMS) e que acometeu rotinas, expectativas de trabalho, consumo, lazer e convivência. Uma crise que tem colapsado sistemas de saúde, horizontes econômicos e perspectivas políticas.

Higienizar constantemente as mãos com água e sabão, janelas e portas abertas para a circulação do ar e/ou aderir ao isolamento social como forma de diminuição do contágio são orientações que não alcançam, por exemplo, as populações mais vulneráveis.

O vírus, mesmo invisível, tem atuado com lupa na exposição das desigualdades sociais. E concordamos que a desigualdade social presente na sociedade "não pode ser entendida sem se tomar em conta os nexos com a herança colonial e as diferenças étnicas que o poder moderno/colonial produziu" (OLIVEIRA; CANDAU, 2010, p. 23).

Com a lupa voltada para a Região Metropolitana do Estado do Rio de Janeiro, que entre suas características marcantes apresenta grande número de favelas e comunidades ${ }^{\mathrm{iii}}$, estão os indivíduos trabalhadores/as autônomos e de serviços essenciais ${ }^{\text {iv }}$. Trabalhadores/as que ao final do dia retornam a complexificação de suas realidades com escassez de água e falta de saneamento básico. Somado a pouca circulação de ar entre becos e quintais presentes nas aglomerações urbanas ${ }^{\mathrm{v}}$ evidencia-se que dentro da desigualdade escancarada outras desigualdades aprofundam a crise de região para região e de profissão para profissão.

Com a emergência da saúde pública decorrente do novo coronavírus, o Governo do Estado do Rio de Janeiro efetuou providencias ${ }^{\mathrm{vi}}$, entre elas a suspensão das aulas nas unidades públicas e privadas de ensino sugerindo a antecipação das férias escolares de forma a não prejudicar o calendário escolar de 2020. Com o aumento no número de contágio e agravamento da situação decretou-se situação de calamidade pública ${ }^{\text {vii }}$ no Estado e a adoção de atividades pedagógicas remotas foi a opção de muitas instituições de ensino.

No cenário da crise, protagonizam discussões que problematizam as circunstâncias desiguais e as não-condições do ensino de forma remota para grande parte dos/as estudantes da rede pública de ensino. Protagonizam instituições que na urgência da emergência recorrem a plataformas e aplicativos para a continuidade de suas atividades. Protagonizam o trabalho e a produtividade parecendo secundarizar o direito à vida e a educação.

Santos (2020) chama atenção para a crise já posta e aprofundada com o advento da pandemia. Para o autor

A actual pandemia não é uma situação de crise claramente contraposta a uma situação de normalidade. Desde a década de 1980 - à medida que o neoliberalismo se foi impondo como a versão dominante do capitalismo e este se foi sujeitando mais e mais à lógica do sector financeiro-, o mundo tem vivido em permanente estado de crise. Uma situação duplamente 
anómala. Por um lado, a ideia de crise permanente é um oximoro, já que, no sentido etimológico, a crise é, por natureza, excepcional e passageira, e constitui a oportunidade para ser superada e dar origem a um melhor estado de coisas. Por outro lado, quando a crise é passageira, ela deve ser explicada pelos factores que a provocam. Mas quando se torna permanente, a crise transforma-se na causa que explica tudo o resto. Por exemplo, a crise financeira permanente é utilizada para explicar os cortes nas políticas sociais (saúde, educação, previdência social) ou a degradação dos salários. (SANTOS, 2020, s/p).

Dentre as tramas deste cenário, o objetivo deste artigo é discutir os sentidos da docência em tempos de pandemia e para isso buscamos visibilizar narrativas em experiências de relações, territórios e desafios de ser professor/a no contexto da docência em atividades remotas.

Procuramos escutar e refletir com e a partir de relatos de experiência de professoras e professores da educação básica sobre o que é dar aula em tempos de pandemia. Para tal discussão, o texto está organizado em cinco partes: na primeira serão apresentados alguns apontamentos teóricos que nos ajudarão a compreender o cenário atual de incertezas e crise, na seção seguinte iremos apresentar quem são as professoras e o professor que fazem parte da nossa investigação. Os dois itens seguintes apresentam as falas dos/as docentes e suas problematizações. Terminamos o texto trazendo algumas questões, levantando hipóteses, procurando fomentar reflexões.

\section{Luz, câmera, (desumaniz)ação}

Diante de tensões e disputas, quais são as luzes e sombras do trabalho pedagógico no exercício de atividades escolares realizadas em domicílio? Entre o pedagógico e a manutenção da vida prática, o que sentem e pensam os/as docentes que estão atuando neste cenário antes inimaginável?

O interesse em refletir tais questões recorre do reconhecimento ${ }^{\text {vii }}$ das lutas políticopedagógicas e emocionais presentes nas circunstâncias do ensino remoto com vistas a dar uma contribuição significativa para a compreensão da situação atual. Diante dessa excepcionalidade é preciso ser sensível. Este trabalho se propõe a colocar em diálogo o lugar das narrativas e as questões que entrecruzam a vida de quem tem exercido atividade profissional no cenário da crise do novo coronavírus. Vida, trabalho, saúde, organização e atividade social atual e futura precisam ser visibilizadas como forma de ampliação no debate a precariedade das condições de trabalho e anulação da individuação dos docentes. Professoras 
e professores merecem ser considerados em seu trabalho, vida, segurança e bem estar. Por este quadro, o presente trabalho se propõe a refletir sobre essas tensões e disputas, luzes, sombras e ação pedagógica.

A escola que conhecemos antes da necessidade do distanciamento social, pouco promove a emancipação dos sujeitos e/ou vem alterando o modo de vida das pessoas e promovendo justiça social. O esforço em tratar a todas e todos em um ideal de igualdade esbarra em negligenciar as diversidades e diferenças presentes no cotidiano escolar. Mesmo tendo presente experiências outras que se assumem insurgentes, a educação escolar insiste no debate entre teoria e prática quando nenhum aditivo deveria separar tais proposições. A escola e as relações/ações em seu interior careceriam, portanto, de uma reinvenção (CANDAU, 2015).

No entanto, o reinventar da escola precisa passar por diversas instâncias. É impossível pensar no contexto local da sala de aula sem pensar nas questões estruturais e nos diversos contextos de influência que atravessam as políticas públicas, sejam a nível da Educação Básica, sejam concernentes a formação de professores/as. Os sentidos e dilemas da escolarização já se encontram na ordem do dia da discussão hodierna sobre escola. Candau e Koff (2015) já anunciavam que a educação escolar se encontra em crise. As autoras sinalizam que

\begin{abstract}
Muitas são as discussões atuais sobre o sentido da escolarização, os desafios que enfrentam os sistemas de ensino, a problemática cotidiana da educação escolar, particularmente o Ensino Fundamental e Médio. Basta ler os jornais diários de ampla circulação e/ou assistir os jornais televisivos para constatar a pluralidade de questões que atravessam hoje a dinâmica escolar. A escola está na ordem do dia: universalização da escolarização, qualidade da educação, projetos político-pedagógicos, dinâmica interna das escolas, concepções curriculares, relações com a comunidade, função social da escola, gestão educacional, sistemas de medição no plano internacional e nacional, formação e condições de trabalho de professores/as, manifestações de violência e bullying na escola, entre outras (CANDAU; KOFF, 2015, p. $331)$.
\end{abstract}

A reinvenção da escola não se atém apenas à prática pedagógica do/a educador/a, mas também a sua formação inicial. Candau (2006) fala de três elementos imprescindíveis para a construção de uma nova escola, mais justa e igualitária: reconhecer nossas identidades culturais, identificar nossas representações do que chamamos de "outros/as" e conceber a prática pedagógica como um processo de negociação cultural.

Canário (2008) sinaliza sobre as mutações presentes na escola tendo em conta a presença de atores igualmente suscetíveis às transformações presentes na sociedade - como 
uma retroalimentação. De acordo com o autor, é possível relacionar que a escola sofreu mutações que se relacionam com as mutações sociais.

$\mathrm{Na}$ primeira metade do século XX a escola era vista como um modo de formar cidadãos, transmitia valores e ofertava base para a futura inserção na divisão do trabalho, configurando a escola como um lugar de certezas. Após a Segunda Guerra Mundial, as políticas públicas geraram crescimento do acesso à escola, fazendo com que ela deixasse de ser elitista e passasse a atender também as massas. Os pensamentos que associavam a escola com a esperança de desenvolvimento, igualdade e mobilidade social ajudaram a compor um cenário de uma escola de promessas. Mas a partir dos anos setenta pesquisas mostram a ausência entre oportunidades educativas e oportunidades sociais, verifica-se a falência das promessas da escola.

A investigação sociológica encarregou-se de demonstrar a inexistência, quer de uma relação de linearidade entre as oportunidades educativas e as oportunidades sociais, quer de uma relação linear entre democratização do ensino e um acréscimo de mobilidade social ascendente. A sociologia da "reprodução" pôs em evidência o efeito reprodutor e amplificador das desigualdades sociais, desempenhado pelo sistema escolar. (CANARIO, 2008, p. 75).

A democratização do acesso acabou por envolver a escola em uma produção de desigualdades sociais configurando-a como um espaço de incertezas, localizando questões e desafios à escola que até mesmo podem estar relacionadas entre si: a superação e a busca de sentido na escola. Por um momento, com a ampliação do acesso à informação e as novas tecnologias, alguns estudantes questionam-se se a escola ainda precisaria existir. A resposta vem quando pontuamos o papel social que ela exerce.

A pauta torna-se tratar e superar a reprodução das desigualdades sociais que se relaciona com a falta de sentido da escola. O trabalho de Costa e Momo (2009) já anunciava a escola como um lugar de conveniência para muitos setores, em especial o do capital. Ao mencionarem o conjunto de "utilidades da escola" indicavam "sua inequívoca conexão com políticas neoliberais regidas pela atenção primordial às movimentações de mercado" (p. 522), trazendo à tona a relação aluno-cliente utilizando-se do potencial catalizador de agenciamento cultural da escola para responder a estratégias de marketing.

Em tempos de crise nas instituições e sobre a legitimidades das mesmas, precisamos recuperar e enfrentar questões que vulnerabilizam a escola e os novos tempos. "Tudo parece concorrer para afirmar a homogeneização e padronização" (CANDAU, 2015, p. 5). Mais uma vez, entre discussões e movimentos, o que nos falta? A escola tem futuro? 
Durante a necessidade do distanciamento social e suspensão das atividades presenciais, a crise do novo coronavírus tem sugerido diversos lugares sociais para a escola, e especialmente, o trabalho docente. Para muitos/as, nada parece substituir as relações do cotidiano escolar, para outros/as muitos/as a transmissão do conteúdo e a garantia da realização do ano letivo é o que mais satisfaz. Entre as duas opções está a precariedade das condições de trabalho entre os/as docentes. Precariedades que expõem estruturas da Rede Privada e Pública de Ensino que prescrevem ações pautadas na lógica de mercado em critérios que pouco se aproximam de saúde e bem comum, desvalorizando o papel social da escola e o trabalho docente.

A precarização do trabalho docente necessita ser pauta de discussões e análises. As inadequadas condições de trabalho, seguidas a ambiência de desconfiança acerca do ofício de ser professor/a desumanizam as relações de convivência e aprendizagem que deveriam ser, por si só, enriquecedoras e humanas.

Candau e Koff (2015) explicitam que

Junto às condições de trabalho precárias que a grande maioria dos/as professores/as vive, é possível detectar um crescente mal-estar entre os profissionais da educação. Insegurança e stress parecem cada vez mais acompanhar o dia a dia dos docentes. Sua autoridade intelectual e preparação profissional são frequentemente questionadas. $\mathrm{O}$ impacto das tecnologias da informação e da comunicação sobre os processos de ensino-aprendizagem obriga a buscar novas estratégias pedagógicas. Os sujeitos da educação, crianças e adolescentes, apresentam configurações identitárias e subjetividades fluidas que escapam à compreensão dos educadores/as. Diante deste quadro muitos/as evadem da profissão e procuram caminhos mais tranquilos e seguros de exercício profissional. Tendo presente esta realidade sombria, é possível detectar diferentes modos de abordá-la (CANDAU; KOFF, 2015, p. 331).

Para Nóvoa (2007) há alguns anos os/as professores/as têm passado por momentos difíceis com a diminuição do seu prestígio desde o pós-guerra e a redução do seu papel a competências e técnicas profissionais, esvaziados/as da sua função social e constantemente ameaçados/as por utopias que em tempos anteriores falavam da sua substituição por sistemas e mecanismos não humanos. Hoje cogitam a não presença do/a professor/a no processo educativo acontecido em domicílio, o "homeschooling".

Outras tensões acompanham a crise do novo coronavírus. Tanto para o macroorganismo em suas políticas educacionais, quanto para o micro-organismo recorrente das práticas pedagógicas. Em tempo algum, e, essencialmente neste tempo presente, é demasiado reiterar que a Educação não é neutra. A conjuntura da formação social capitalista que temos, 
somadas as mudanças provocadas por crises internas e externas tem fundamentado práticas excludentes firmadas no contexto de universalidade científica historicamente eurocentradas. Tomadas de decisões e orientações, inclusive, que evidenciam o Estado não para efeitos de democracia e cidadania, mas como gestor de mortes, criando situações para que as pessoas não vivam. Regredindo em sua capacidade e dever, mas progredindo com uma pandemia intermitente "[...] subjuga[ndo] a vida ao poder da morte (necropolítica)" (MBEMBE, 2018, p. 71).

Mbembe (2018) discorre sobre o conceito de soberania, tendo sua expressão máxima no poder de decidir quem pode viver e quem pode morrer. $\mathrm{O}$ autor adiciona

Minha preocupação é com aquelas formas de soberania cujo projeto central não é a luta pela autonomia, mas a "instrumentalização generalizada da existência humana e a destruição material dos corpos humanos e populações". Tais formas da soberania estão longe de ser um pedaço de insanidade prodigiosa ou uma expressão de alguma ruptura entre os impulsos e interesses do corpo e da mente. De fato, tal como os campos da morte, são elas que constituem o nomos do espaço político em que ainda vivemos. Além disso, experiências contemporâneas de destruição humana sugerem que é possível desenvolver uma leitura da política, da soberania e do sujeito, diferente daquela que herdamos do discurso filosófico da modernidade. Em vez de considerar a razão a verdade do sujeito, podemos olhar para outras categorias fundadoras menos abstratas e mais palpáveis, tais como a vida e a morte (MBEMBE, 2018, p.11).

A morte hoje tem sido categoria palpável para se pensar o momento atual. Neste cenário que se coloca com o advento da pandemia, existem discussões que se contrapõem. Por um lado, há a defesa de que um "novo normal presencial" precisa ser retomado rapidamente e desta forma, assim como nos episódios de guerra, a morte de alguns/mas, muitos e muitas seria justificada para a garantia da economia. Por outro lado, há a defesa da vida e do isolamento social, entendendo que a vida física se sobrepõe às questões do mercado capitalista. O que parece ser interessante pensar é que a partir da leitura de necropolítica de Mbmebe (2018) que se baseia na ideia de biopoder já trazida por Michel Foucault (1997), o estado hoje tem em suas mãos as decisões acerca das vidas que são colocadas em risco para se manter outras vidas que dentro de uma lógica colonial capitalista seriam vistas como mais importantes.

Neste sentido, a pandemia intensificou a necessidade de um posicionamento contra hegemônico e insurgente. Assim, em atenção às aspirações em defesa de uma Educação para todas e todos, começamos por ouvir seis professoras e um professor que lecionam entre a 
Educação Infantil e o Ensino Médio de escolas da rede pública e privada nas cidades de São Gonçalo, Niterói e Rio de Janeiro.

\section{Sobre lugar de fala: quem são os/as nossos/as professores/as?}

Não pretendemos aqui dar voz as professoras e ao professor, pois entendemos que elas e ele têm a sua própria voz, no entanto, procuramos garantir uma escuta atenta à problemática acerca do novo cenário criado pela pandemia, cenário este que tem criado novas demandas no fazer docente.

De acordo com Ribeiro (2017) todas as pessoas possuem lugar de fala pois a localização a qual a autora se refere é social. O que se faz necessário é a quebra de um sistema ainda vigente que escolhe quais narrativas merecem ser ouvidas. Neste sentido, procuramos falar "com" e não "sobre" e nem "pelo/as" docentes, respeitando seus lugares de fala.

O convite para colaboração voluntária com as reflexões aqui já postas foi socializado em redes sociais, empregando contatos que uma das autoras possui. A amostra pretendida era de até dez participantes, mas face as demandas de trabalho entre reuniões, planejamentos e aulas remotas alguns sujeitos contactados optaram por não participar. O critério para o convite era a utilização das redes sociais virtuais pessoais de professoras e professores que manifestaram a nova rotina de trabalho. Após aceite, elaboramos um roteiro de perguntas abertas para captar os relatos. A entrevistas foram realizadas por chamadas telefônicas individuais via aplicativo de mensagens virtuais.

Destarte, conforme o Quadro 1 a seguir, formou-se o conjunto de professoras e professor cujo relatos possibilita reflexões, debates e escuta de narrativas únicas, mas que poderão estabelecer similaridades e contrastes tanto entre elas, mas, especialmente, entre demais professoras e professores que estão em trabalho remoto no contexto de emergência e crise do novo coronavírus. 


\section{QUADRO 1 - Conjunto de Professoras e Professor}

\begin{tabular}{|c|c|c|c|c|}
\hline CODINOME $^{\text {ix }}$ & $\begin{array}{c}\text { FORMAÇÃO } \\
\text { INICIAL }\end{array}$ & $\begin{array}{c}\text { EXPERIÊNCIA } \\
\text { EM SALA DE } \\
\text { AULA } \\
\text { PRESENCIAL }\end{array}$ & $\begin{array}{l}\text { REDE PRIVADA/ } \\
\text { QUANTIDADE } \\
\text { DE ESCOLAS }\end{array}$ & $\begin{array}{l}\text { REDE PÚBLICA/ } \\
\text { QUANTIDADE } \\
\text { DE ESCOLAS }\end{array}$ \\
\hline LUANA & $\begin{array}{l}\text { LICENCIATURA EM } \\
\text { HISTÓRIA }\end{array}$ & 5 ANOS & $\begin{array}{l}6^{\circ} \text { AO } 9^{\circ} \text { ANO DO } \\
\text { FUNDAMENTAL } \\
2^{\circ} \text { E } 3^{\circ} \text { ANOS DO } \\
\text { ENSINO MÉDIO }\end{array}$ & NÃO \\
\hline MARCOS & $\begin{array}{l}\text { CURSO NORMAL/ } \\
\text { CURSO DE INGLÊS }\end{array}$ & 9 ANOS & $\begin{array}{l}\text { EDUCAÇÃO } \\
\text { INFANTIL } \\
1^{\circ} \text { AO } 5^{\circ} \text { ANO DO } \\
\text { ENSINO } \\
\text { FUNDAMENTAL } \\
1^{\circ} \text { AO } 5^{\circ} \text { ANO DO } \\
\text { ENSINO } \\
\text { FUNDAMENTAL }\end{array}$ & NÃO \\
\hline NIVIA & $\begin{array}{l}\text { LICENCIATURA EM } \\
\text { PEDAGOGIA }\end{array}$ & 10 ANOS & $\begin{array}{l}\text { EDUCAÇÃO } \\
\text { INFANTIL }\end{array}$ & NÃO \\
\hline OLINDINA & $\begin{array}{l}\text { CURSO NORMAL/ } \\
\text { LICENCIATURA EM } \\
\text { LETRAS- } \\
\text { LITERATURA }\end{array}$ & 4 ANOS & $\begin{array}{l}6^{\circ} \mathrm{E} 7^{\circ} \mathrm{ANO} \\
\text { ENSINO } \\
\text { FUNDAMENTAL }\end{array}$ & $\begin{array}{c}\text { ENSINO } \\
\text { FUNDAMENTAL } \\
2^{\circ} \text { ANO }\end{array}$ \\
\hline PAULA & $\begin{array}{l}\text { LICENCIATURA EM } \\
\text { PEDAGOGIA }\end{array}$ & 7 ANOS & $\begin{array}{l}1^{\circ} \text { ANO ENSINO } \\
\text { FUNDAMENTAL }\end{array}$ & $\begin{array}{l}\text { EDUCAÇÃO } \\
\text { INFANTIL }\end{array}$ \\
\hline QUEILA & $\begin{array}{l}\text { LICENCIATURA EM } \\
\text { QUIMICA }\end{array}$ & 3 ANOS & $\begin{array}{l}2^{\circ} \text { E } 3^{\circ} \text { ANOS DO } \\
\text { ENSINO MÉDIO }\end{array}$ & NÃO \\
\hline RITA & CURSO NORMAL & 3 ANOS & $\begin{array}{l}\text { EDUCAÇÃO } \\
\text { INFANTIL }\end{array}$ & NÃO \\
\hline
\end{tabular}

Fonte: as autoras, 2020.

Como já mencionado anteriormente, seis professoras e um professor participaram da nossa pesquisa, sendo sete indivíduos no total. Quatro professoras trabalham no município de São Gonçalo. Uma delas trabalha na cidade de São Gonçalo e na cidade de Niterói. Três relatos são experiências de trabalho em instituições na cidade do Rio de Janeiro. Em preservação aos sujeitos deste trabalho, os codinomes são fictícios. Temos então as falas de Luana, Marcos, Nivia, Olindina, Paula, Queila e Rita.

\section{Entre o pedagógico e a manutenção da vida}

A partir da escuta dessas professoras e professor, elucidaremos alguns aspectos que deflagram realidades e não-prioridades na circunstância do ensino remoto no período da pandemia. Afinal, o que é ser professora e professor em tempos de pandemia e a necessidade de distanciamento social? 
Luana é professora de história e trabalha em duas escolas, cada uma em uma cidade diferente. A fala de Luana apresenta o movimento feito pela escola privada onde atua em São Gonçalo:

Na escola em São Gonçalo, a direção não fez movimentação de atividade e acreditou que fossem apenas os 15 dias dados pelo Estado. Só na segunda semana que ela solicitou que fizéssemos um plano de estudo. Nem era criação, mas sugestão de material que seria enviado por grupo de mensagem. Mas abril chegou e trouxe a cobrança por parte dos pais: "colocar meu filho pra ver vídeo no Youtube? Isso eu mesmo coloco!". Chegou ao grupo de mensagem dos professores que os responsáveis iriam boicotar o pagamento das mensalidades. Foi quando nós - os professores nos organizamos e procuramos uma ferramenta de aula ao vivo para trabalhar. Em nenhum momento fomos cobrados da direção, mas como é uma escola de bairro ia acabar recaindo no nosso salário. Sofremos muito. Como aplicativo é gratuito sempre cai muito.

Luana fala da iniciativa dos/as próprios/as professores/as na criação de estratégias para que os responsáveis não parecem de pagar as mensalidades. Ainda que afirme não ter sido cobrada pela escola, inicialmente a escola já solicitou a realização de um plano de estudo e não nos parece ter oferecido nenhuma estrutura para que as atividades on line ocorressem.

Na escola privada em Niterói onde atua, Luana compartilha que:

A escola já vinha passando por modernização e conta com interação virtualizada entre os comunicados da escola, professores e pais. Sempre teve agenda digital, trabalhos e atividades para casa, por exemplo. Quando a quarentena foi decretada a administradora da escola vislumbrou que duraria mais tempo. Não houve interrupção no trabalho, continuamos o uso da plataforma e fomos enviando exercícios de revisão. Ela deve ter investido mais e muito rápido o aplicativo recebia nossos vídeos com os conteúdos gravados. $O$ difícil era o contato com os alunos. Eles não aderiram ao fórum, era contato zero.

Luana apresenta uma outra realidade, onde a escola parece fornecer estrutura necessária, no entanto apresenta a problemática da não aderência dos/as estudantes para a participação das atividades propostas pela unidade escolar. Quando perguntada sobre o que poderia estar causando a não aderência por partes dos/as estudantes ao fórum, Luana parece não ter feito nenhuma avaliação sobre a situação. Afirma que logo em seguida vieram as aulas virtuais ao vivo. Mas alguns questionamentos cabem: por que os/as estudantes não participam das atividades? Falta de interesse? Não apresentam os dispositivos necessário para o acompanhamento das atividades? Estão passando por dificuldades psicológicas que os/as impedem de participar das atividades? A escola consultou estudantes e responsáveis sobre o envio de exercício e realização de atividades no período da pandemia? 
Marcos é professor na cidade do Rio de Janeiro. Trabalha em três escolas da rede privadas. São instituições e segmentos diferentes, “mas calma, são geograficamente próximas!".

Tem uns dois anos que têm sido muito angustiante trabalhar com Educação, agora com a pandemia esse peso aumentou um pouco mais. Antes de você me ligar eu estava pensando no Darcy Ribeiro, bem que ele falou... é um projeto dos mais bem executados... A gente nunca passou por uma situação como essa e a gente está tendo que se reinventar...pode até ser interessante o ingresso na tecnologia, mas não sei não. Eu era "tecnofóbico", mas na marra isso foi superado pra atender as escolas e continuar a dar minhas aulas. Nos primeiros 15 dias sem ir à escola eu me senti um banco de questões. Eu acordava e já tinha (mensagem com) pedido de folhinha. Agora faz isso. Agora faz aquilo. No meio disso tudo eu produzia e produzia, foi quando me deu conta que a solicitação de material era para a turma de maternal! Mas eu tinha que fazer, mesmo sem estar ou saber se alguém está preocupado com o aprendizado. Eu sou terceirizado e assim que começou a pandemia contratos de amigos meus foram cancelados. Assim a carga foi ficando muito pesada, uma loucura. Salário de março que ainda não recebi. Me diz um professor nessas condições... Pais, especialmente da Educação Infantil estavam tirando da escola e a escola o tempo todo colocando a responsabilidade na gente e nas nossas folhinhas para que os alunos fiquem na escola. Eu me vi trabalhando o dia inteiro pra uma das escolas em que eu só trabalho as sextas!

Marco sinaliza em sua fala a dificuldade em trabalhar na área de educação, antes da pandemia. Sua realidade é diferente àquela apresentada por Luana, pois desde o início do afastamento social já sofre com as demandas solicitadas pela escola, apresentando a ameaça real de ser dispensado. Fica evidente que a carga horária de trabalho aumentou, mesmo tendo o salário atrasado. Para o professor o retorno "à normalidade" seria o mais viável, mas de que normalidade estamos falando?

De acordo com Santos (2020) precisamos refletir sobre a ideia de normalidade e o que almejamos quando desejamos o retorno ao padrão de vida anterior a pandemia. Se foi a suposta "normalidade" que nos colocou no aprofundamento de diversos aspectos que deflagram a crise mundial pela qual passamos, precisamos insurgir e criar nossas possibilidades para a desconstrução de uma nova realidade. No entanto, para o autor

[...] ] regresso à «normalidade» não será igualmente fácil para todos. Quando se constituirão os rendimentos anteriores? Estarão os empregos e os salários à espera e à disposição? Quando se recuperarão os atrasos na educação e nas carreiras? Desaparecerá o Estado de excepção que foi criado para responder à pandemia tão rapidamente quanto a pandemia? Nos casos em que se adoptaram medidas de protecção para defender a vida acima dos interesses da economia, o regresso à normalidade implicará deixar de dar prioridade à defesa da vida? Haverá vontade de pensar em alternativas quando a alternativa que se busca é a normalidade que se tinha antes da quarentena? 
Pensar-se-á que esta normalidade foi a que conduziu à pandemia e conduzirá a outras no futuro? (SANTOS, 2020, s/p).

Nívea, assim como Marcos é professora da Educação Infantil em uma instituição da rede privada do Rio de Janeiro. Em seu relato Nívea expõe que a escola em que trabalha está localizada em um bairro de classe média da cidade do Rio de Janeiro. Comentou o movimento dos pais que requisitaram descontos nas mensalidades, mas que na reivindicação deles estava a solicitação de que o pagamento de todos os funcionários fosse assegurado.

"Os pais fecham com a gente. São artistas, empreendedoras da área da cultura e isso facilita em nos reconhecer e valorizar". Nívea compartilhou também que a estratégia da instituição é chamar de encontro e não aula o que estão realizando durante o período da pandemia. De acordo com ela

O trabalho tem sido duro, mais que isso, tem sido conflitante. É contra o que eu estou acostumada. A Educação Infantil é muito pouco de tela de computador. Como a tela vai ser o que temos em sala? Tela não tem relação. Eu planejo atividades, histórias, gincanas, mas o tempo todo fico me perguntando o que eu estou fazendo...e eu sei que não vou ter resposta. Eu acho tudo muito estranho, mesmo gostando muito de tecnologia. Mas na Educação Infantil é complexo. A tecnologia é uma ferramenta. O olho no olho é insubstituivel. Eu acho que a gente está fazendo isso mais pra comprovar um salário, sabe?

Sobre a relação com as atividades, Nívea descreve que os responsáveis de seus/suas alunos/as parecem não entender a proposta da escola que seria manter o vínculo, segundo ela "eles não sabem o que fazer com as crianças. Eles acham que é pra ocupá-las enquanto eles trabalham. E não é!”

Olindina é professora em duas instituições. Leciona para o $2^{\circ}$ ano do Ensino Fundamental na Rede Municipal e no $6^{\circ}$ e $7^{\circ}$ anos na Rede Privada, ambas escolas na cidade de São Gonçalo. Olindina descreve que "na escola pública é a escola lutando o tempo todo". O município de São Gonçalo suspendeu as aulas e conforme o decreto $n^{\circ} 057 / 2020^{\mathrm{x}}$ sugeriu que fossem enviadas atividades pedagógicas para os estudantes da rede. A fala de Olindina apresenta alguns incômodos:

O decreto não é claro e não orienta a gente em nada. Diz que é bom que a gente envie, mas envia como? Por onde? Tem coisas que só a Prefeitura pode fazer. Não tem como a Diretora decidir. O que eu gosto da escola pública é que a gente aprende a ser humano. A gente precisa se posicionar e mexer na estrutura e isso humaniza a gente o tempo todo. 
No que diz respeito a escola privada, Olindina apresenta outro cenário, falando sobre o prestígio da escola: "Tem alunos até de Niterói. Sempre teve material, data show e plataforma on-line".

Paula, assim como Olindina, trabalha na Rede Municipal e na Rede Privada de Ensino, mas na cidade do Rio de Janeiro. Na instituição da Rede Pública leciona em uma creche no Morro da Formiga, no bairro da Tijuca que não tem ofertado atividade remota durante o período de suspensão das aulas presenciais, conforme identificamos em seu depoimento: “ $\mathrm{Na}$ rede social da escola tem material informativo e umas indicações de brincadeiras, mas de forma informal. Não tem um compromisso".

$\mathrm{Na}$ instituição em que trabalha com estudantes do $1^{\mathrm{o}}$ ano do Ensino Fundamental de uma instituição da Rede Privada de Ensino, Paula compartilhou que a instituição fez um grande esquema de trabalho:

Assim que saiu o decreto a gente teve formação de ferramentas do Google for School. A escola deu todo suporte. Fez um levantamento da nossa internet, se tínhamos computador. Pareceu bem comprometida a manter a qualidade do trabalho".

Paula assim como Olindina apresentam diferenças entre as escolas públicas e privadas onde atuam. Nos parece que as escolas privadas já acompanhavam as exigências que o mundo digital vem impondo à contemporaneidade, tendo Paula trazendo em seu discurso a importância dessas tecnologias para a qualidade do trabalho docente.

Queila é professora de química na Rede Privada de Ensino na cidade de Niterói. Assim como Paula, relatou que também sente um vazio nas aulas remotas e apresenta suas preocupações:

Os alunos demonstravam dificuldade com a matéria, mas eu estava lá e via na cara deles e me reinventava pra explicar de novo. Agora, nem sempre eles estão com a câmera aberta. Não é sempre que vejo a cara de quem entendeu e de quem não entendeu. Sem contar que alguns que não entendem me enviam solicitações de ajuda o tempo todo. Não tem horário de aula. A demanda de trabalho aumentou muito. É treinamento e reunião aos montes. Toda hora um questionário para os alunos falarem das aulas...e a gente fica inseguro. Eu me sinto numa empresa em que o cliente sempre tem razão e com isso a gente não sabe até onde a gente se mantem. Em uma das reuniões perguntou sobre o nosso bem estar. Vários professores comentaram sobre a demanda dos fóruns e tocamos na nossa saúde mental, mas no plano prático nada foi sugerido. Ficou jogado na reunião.

Queila levanta uma importante questão que reverbera acerca do papel da escola. A professora diz que ao se deparar com as dificuldades de seus/suas estudantes anteriormente 
em suas aulas (presenciais), se reinventava. A relação professor/a-aluno/a estabelece o que Tardif (2012) chama de saberes da experiência e estes se desenvolvem no cotidiano da escola, a partir das práticas e discursos próprios do chão da escola. Seria possível pensar em relações a partir do novo modelo de aulas remotas? Como fazer a leitura das reações corporais dos/as estudantes, expressões, olhares, o movimento excessivo das pernas? Será que o/a professor/a precisará desenvolver outros saberes para lidar com a proposta de aulas remotas? Que saberes serão estes? Saberes da experiência a distância? E como criar um ambiente onde estudantes e docentes se sintam conectados/as, seguros/as?

Rita é professora da Educação Infantil em uma escola da Rede Privada de Ensino em São Gonçalo. Compartilhou experiências semelhantes à de Queila, especialmente sobre sua saúde mental, mas também sobre sua integridade física:

\footnotetext{
Quando tudo isso começou eu sabia que ia demorar. Minha prima mora na Itália e falou coisas terriveis do que estava acontecendo em lá por causa do virus. Assim que as aulas foram suspensas eu procurei a coordenadora e falei que seria complicado gravar aulas. Eu não tenho computador. Quando precisava usar, usava na escola. Sabe o que a coordenadora me respondeu? Que eu devia dar um jeito ou continuar vindo a escola gravar, porque esse era o novo normal. Eu fiquei muito abalada com aquilo, sabe? Pegar ônibus seria um problema. A cidade com a quantidade de casos aumentando, mas eu não tive escolha. É o que tenho feito nesses dias. Quando dá pego um uber e me organizo pra gravar tudo em uma ida só. O bom é que são só três vídeos por semana, isso me facilitou.
}

O relato de Rita nos reporta ao conceito de necropolítica discutido por Mbembe (2018). Para que a escola cumpra a tarefa de manter suas atividades a professora deve "dar um jeito" arriscando sua própria vida e assim protegendo a instituição que merece ser mantida. A vida é posta em risco para que o aspecto econômico, no caso da escola (e até mesmo da professora) seja preservado. A instituição para continuar fazendo o pagamento dos/as funcionários/as precisa oferecer as atividades pedagógicas de maneira remota, pois os/as estudantes precisam ter suas vidas preservadas e com garantia de progresso educacional. Já os/as professores/as para garantir seus empregos e salários colocam suas vidas em risco. Apresenta-se o que vamos chamar de paradoxo da pandemia.

\section{Que é ser professor/a em tempos de pandemia?}

Mendonça (1997) ao realizar uma pesquisa histórica já anunciava diferentes deslocamentos acerca do papel do/a professor/a na sociedade. Tem como tese de que o/a 
professor/a deve ser um/a intelectual e não burocrata. Para Candau (2006) o/a professor/a precisa se reinventar sendo concebido/a como um agente cultural.

François Dubet em entrevista intitulada "Quando o sociólogo quer saber o que é ser professor", discute sobre a ideia de professor/a eficiente:

O problema é que não se sabe o que determina o efeito professor. O método pedagógico escolhido não faz a diferença. Os homens não são mais eficientes que as mulheres, os antigos não mais que os novos. Há velhos professores totalmente ineficientes e pessoas que começam eficientes logo na primeira semana. A ideologia do professor também não tem nenhum efeito. O único elemento que parece desempenhar um papel é o efeito Pigmaleão, isto é, os professores mais eficientes são em geral aqueles que acreditam que os alunos podem progredir, aqueles que têm confiança nos alunos. Os mais eficientes são também os professores que veem os alunos como eles são e não como eles deveriam ser. Ou seja são os que partem do nível em que os alunos estão e não aqueles que não param de medir a diferença entre o aluno ideal e o aluno de sua sala. Mas evidentemente, nas atitudes particulares, entram também orientações culturais gerais, interesses sociais, tipos de recrutamento e de formação. Não são apenas problemas psicológicos (PERALVA \& SPOSITO, 1997, p. 222).

Temos diversos autores e autoras que ao longo da história discutiram sobre o papel e sobre ofício de ser professor/a, levantando aspectos desde sua formação continuada até sua prática pedagógica, no entanto um novo cenário se apresenta onde o ser professor/a ganha novos contornos, transformando-se no tornar-se professor/a em meio a pandemia.

Quando questionada acerca do que é ser professor/a em tempos de pandemia, Luana responde a partir de diferentes narrativas:

Parece fácil, mas não é. A gente fala com gente e não com câmera. Na câmera gaguejo, não sei se estão me entendendo, não vejo a cara deles (...). Tem também que na minha casa o ambiente não é confortável...não tenho mais mesa...o horário sem barulhos externos para gravação e sem minha filha são só depois das onze da noite. A professora dorme quase uma hora da manhã e a mãe acorda às seis horas. Mas a gente está ali, lidando com telas vazias, mas tem que estar ali. E isso é muito desagradável e longe da realidade...desmotiva, sabe? A verdade é que eu percebo em colegas que todos nós estamos preocupados em tentar fazer o melhor, mas lidando com a situação e as aulas ao vivo... a gente tem certeza de que esse nosso melhor não é suficiente, porque não é a escola.

Marcos persegue uma ideia sobre as atividades remotas: "São ações da escola querendo mostrar que está trabalhando, para que os pais paguem a mensalidade...porque muitos pais especialmente da educação infantil estavam tirando da escola”. Ainda de acordo com seu relato: 
A escola o tempo todo colocando a responsabilidade nos professores para que os alunos fiquem na escola. tem que fazer videozinho. folhinha. Eu me vi trabalhando o dia inteiro. Eu, que só trabalha às sextas meus colegas foram demitidos e eu estava em frangalhos. Na quarta era plataforma, na quinta já estava em aula ao vivo. Tudo isso sem preparação. E eu estou nessa situação, mergulhado nela tentando voltar pra superfície, mas é uma sobrecarga de trabalho que nem sei.

Queila registra que "a escola está fazendo corte e a gente não sabe até onde a gente se mantem. Vivemos em um dilema”. A professora adiciona:

A demanda de trabalho aumentou muito. A todo momento a gente tem uma frequência de reuniões nessa situação de pandemia. Os alunos resistem e desacreditam no regime. Ai a escola fala de saúde mental no discurso, mas não no plano prático. Porque as solicitações fora do horário de trabalho foram normalizadas, o chat vem a qualquer hora pra falar qualquer coisa.

Paula afirma que:

Não colocaria tantas demandas para as crianças, mas a escola que mostrar sua parte do contrato e eu vou junto mostrando o meu trabalho. Mas a gente ve pelas planilhas que circulam nos grupos de mensagem que muitas crianças não entram. Tem criança que nunca foi. Como vamos voltar pra escola? Todos são iguais? Em que é estará o conteúdo? As tarefas que eles fazem, quando fazem nem retornam pra gente!

A partir dos depoimentos analisados constatamos que a precarização do trabalho docente foi aprofundada a partir do isolamento social provocado pela pandemia. Os professores e professoras tiveram sua carga horário de trabalho aumentada, sem muitas vezes ter a garantia do pagamento e manutenção do emprego. Outra questão evidenciada pelas falas é na verdade uma lacuna encontrada no que diz respeito considerar a saúde mental ${ }^{\mathrm{xi}}$ dos/as docentes. Não localizamos em suas falas qualquer preocupação por parte das escolas com as condições psicológicas e físicas dos/as docentes.

\section{Tempo de incertezas}

No cenário das ações em emergência as reflexões vão sendo reveladas no processo. As ações pedagógicas realizadas nas atividades remotas relatadas sublinham que a intensificação do trabalho docente também pode se dar por fatores subjetivos despertados pelas condições objetivas de mudanças no ambiente escolar e no seu entorno. Entre a escolha dos dispositivos e aplicativos para a realização das aulas, entre as tensões da vida prática e a manutenção de seus empregos são tempos de incertezas e ataques a profissão docente em vias de contestação sobre a produção material e intelectual. 
Esta nova realidade vem exigindo de professores/as e redes de ensino novas habilidades e estratégias para manutenção dos vínculos, de aprendizagens e relações significativas em todas as etapas da educação. Mas é possível identificar a manutenção da profissão docente estritamente no ciclo do cuidado e flexibilizando seu lugar entre ensinar e aprender, assim como parece relativizar a necessidade da sobrevivência sobretudo.

Existem muitas perguntas que ainda temos que fazer, assim como muitas outras narrativas que precisamos visibilizar, no entanto, um grande questionamento nos persegue neste momento de incertezas: quando estaremos livres desta pandemia? Como podemos construir uma nova realidade cotidiana presencial? Santos (2020) nos fornece algumas pistas:

Só com uma nova articulação entre os processos políticos e os processos civilizatórios será possível começar a pensar numa sociedade em que humanidade assuma uma posição mais humilde no planeta que habita. Uma humanidade que se habitue a duas ideias básicas: há muito mais vida no planeta do que a vida humana, já que esta representa apenas $0,01 \%$ da vida existente no planeta; a defesa da vida do planeta no seu conjunto é a condição para a continuação da vida da humanidade. De outro modo, se a vida humana continuar a pôr em causa e a destruir todas as outras vidas de que é feito o planeta Terra, é de esperar que essas outras vidas se defendam da agressão causada pela vida humana e o façam por formas cada vez mais letais. Nesse caso, o futuro desta quarentena será um curto intervalo antes das quarentenas futuras (SANTOS, 2020, s/p).

O tempo é de incertezas, onde instituições e docentes precisam se reinventar a todo momento, tentando compreender uma nova realidade que a cada dia impõe novos desafios. $\mathrm{O}$ vírus não faz escolhas, mas certamente aprofunda a crise social já em curso há anos. Pretendemos com este artigo trazer o debate acerca da precarização do trabalho docente, trabalho este que já vem sucateado por políticas neoliberais de desvalorização da escola enquanto locus de aprendizado, dando lugar a políticas meritocráticas de ranqueamento e de controle das práticas pedagógicas. Sem a intenção de trazer respostas fechadas ou prescritivas, procuramos evidenciar as falas dos/as professores/as dialogando "com" e não "sobre" os discursos dos/as mesmos/as.

\section{Referências}

CANÁRIO, R. A escola das "promessas" às “incertezas". Educação Unisinos 12, n. 2, p.7381, maio/agosto 2008. Disponível em: https://bit.ly/2WSeSVz. Acesso em: 17 jul. 2020.

CANDAU, V. O/A Educador/a como agente cultural. In: LOPES, A. R. C.; MACEDO, E, F.; ALVES, M. (Orgs). Cultura e politica de currículo. Araraquara: Junqueira \& Marin, 2006, p.37-51. 
CANDAU, V. M. F.; KOFF, A. M. N. S. A Didática Hoje: reinventando caminhos. Educ. Real. Porto Alegre, v. 40, n. 2, p. 329-348, junho de 2015. Disponível em: < https://bit.ly/3hoRIxI >. Acesso em: 17 de julho de 2020.

COSTA, M. V.; MOMO, M. Sobre a "conveniência" da escola. Rev. Bras. Educ., Rio de Janeiro, v. 14, n. 42, p. 521-533, Dec. 2009. Disponível em: < https://bit.ly/30H5gOn >. Acesso em: 17 jul. 2020.

MBEMBE, A. Necropolítica. São Paulo: n-1 edições, 2018.

MENDONÇA, A. W. P. C. O educador: intelectual ou burocrata? Uma perspectiva histórica. In: CANDAU, V. M. (Org). Magistério: construção cotidiana. Petrópolis: Vozes, 1997, p.1129.

NÓVOA, António. Os professores e as histórias da sua vida. In: NÓVOA, A. (Org). Vidas de professores. Porto: Porto Editora, 2007. 11-30.

OLIVEIRA, L. F.; CANDAU, V. M. F. Pedagogia decolonial e educação antirracista e intercultural no Brasil. Educação em Revista, Belo Horizonte, v. 26, n. 1, p. 15-40, 2010. Disponível em: <https://bit.ly/2ZRQwgv>. Acesso em: 17 jul. 2020.

PERALVA, A. T.; SPOSITO, M. P. Quando o sociólogo que saber o que é ser professor: entrevista com François Dubet. Revista Brasileira de Educação. Rio de Janeiro, n.5, Mai/Jun/Jul/Ago, 1997. p.222-23. Disponível em: https://bit.ly/2ZUda7W. Acesso: em 17 jul. 2020.

RIBEIRO, D. O que é lugar de fala? Belo Horizonte: Letramento, 2017.

SANTOS, B. S. A cruel pedagogia do vírus. Coimbra: Almedina, 2020.

TARDIF, M. Saberes docentes e formação profissional. Petrópolis: Vozes, 2012.

\footnotetext{
${ }^{i}$ Mestranda vinculada ao Programa de Pós-graduação em Educação da Pontifícia Universidade Católica do Rio de Janeiro (PUC-Rio) e integrante do Grupo de Estudos sobre Cotidiano, Educação e Cultura(s) (GECEC). Email: nascimento.eps@gmail.com ORCID: https://orcid.org/0000-0003-3591-6804

ii Professora adjunta da Faculdade de Educação da Universidade Federal do Rio de Janeiro (UFRJ), integrante do Grupo de Estudos sobre Cotidiano, Educação e Cultura(s) (GECEC) e integrante do Grupo de Estudos Multiculturais (GEM). E-mail: ritasperrut@gmail.com ORCID: https://orcid.org/0000-0002-1072-1173

iii A utilização do termo pretende visibilizar as realidades, reinvindicações e resistências presentes neste espaço urbano. Tem se em conta a participação da população residente nesses espaços da cidade e o entrecruzamento das linhas invisíveis de cá e de lá que separam as realidades abissais globais.

${ }^{\text {iv }}$ BRASIL, Decreto ${ }^{\circ} 10.282$, de 20 de março de 2020. Define os serviços públicos e as atividades essenciais como medidas adotadas para o enfrentamento da emergência de saúde pública decorrente do novo coronavírus. Disponível em: https://bit.ly/3jxCloA Acesso em: 04 de junho de 2020.

${ }^{\vee}$ Organização de território conforme dados do Instituto Brasileiro de Geografia e Estatísticas.

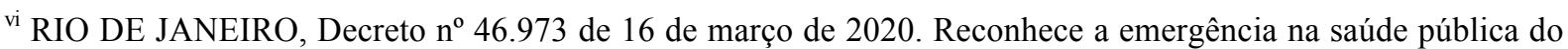
Estado em razão da Covid-19 e dá providencias. Disponível em: https://bit.ly/3eSvXVy Acesso em: 04 de junho de 2020 .
}

Revista Interinstitucional Artes de Educar. Rio de Janeiro, V. 6 - N. Especial II - p. 75-93 (jun - out 2020): "Educação e 92 Democracia em Tempos de Pandemia". DOI: 10.12957/riae.2020.52348 
${ }^{\text {vii }}$ RIO DE JANEIRO, Decreto $n^{\circ} 46.984$ de 20 de março de 2020. Reforça às informações sobre medidas de proteção e conforme o aumento do número de casos no Estado, decreta situação de calamidade pública em razão da Covid-19. Disponível em: https://pge.rj.gov.br/comum/code/MostrarArquivo.php?C=MTAyMzI\%2C Acesso em: 04 de junho de 2020.

viii As autoras estão inseridas no contexto do trabalho remoto no Ensino Superior enquanto Professora e aluna em Estágio Docente de diferentes universidades.

${ }^{\text {ix }}$ Em preservação aos sujeitos deste trabalho, os codinomes são fictícios.

${ }^{x}$ SÃO GONÇALO, Portaria Semed No 057/2020. Suspensão das atividades presenciais na rede Municipal de São Gonçalo. Disponível em : https://www.saogoncalo.rj.gov.br/diario/2020_03_31.pdf Acessado em: 28 de junho 2020.

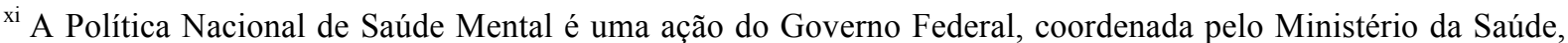
que compreende as estratégias e diretrizes adotadas pelo país para organizar a assistência às pessoas com necessidades de tratamento e cuidados específicos em saúde mental. Disponível em : https://saude.gov.br/saudede-a-z/saude-mental Acessado em: 22 de julho de 2020. 